\title{
Acute kidney injury in non-critical care setting: elaboration and validation of an in- hospital death prognosis score
}

\author{
Jamal Bamoulid ${ }^{1,2,3,4^{*}+}$ (D), Hélène Philippot ${ }^{1 *+}$, Amir Kazory ${ }^{5}$, Maria Yannaraki ${ }^{1}$, Thomas Crepin ${ }^{1,2,3,4}$, \\ Bérengère Vivet ${ }^{1}$, Nadège Devillard ${ }^{1}$, Caroline Roubiou ${ }^{1}$, Catherine Bresson-Vautrin ${ }^{1}$, Jean-Marc Chalopin ${ }^{1,2,3,4}$, \\ Cécile Courivaud ${ }^{1,2,3,4}$ and Didier Ducloux ${ }^{1,2,3,4}$
}

\begin{abstract}
Background: Acute kidney injury (AKI) is still characterized by a high mortality rate. While most patients with AKI are admitted in conventional medical units, current available data are still obtained from studies designed for patients admitted in intensive care units (ICU). Our study aimed to elaborate and validate an in-hospital death prognosis score for AKI admitted in conventional medical care units.
\end{abstract}

Methods: We included two prospective cohorts of consecutive patients with AKI admitted between 2001 and 2004 (elaboration cohort (EC)) and between 2010 and 2014 (validation cohort (VC)). We developed a scoring system from clinical and biological parameters recorded at admission from the EC to predict in-hospital mortality. This score was then tested for validation in the VC.

Results: Three-hundred and twenty-three and 534 patients were included in the EC and VC cohorts, respectively. The proportion of in-hospital death were $15.5 \%$ (EC) and $8.9 \%$ (VC), mainly due to sepsis. The parameters independently associated with the in-hospital death in the EC were Glasgow score, oxygen requirement, fluid overload, blood diastolic pressure, multiple myeloma and prothrombin time. The in-hospital death prognosis score AUC was $0.845+/-0.297(p<0.001)$ after validation in the VC.

Conclusions: Our in-hospital death prognosis score is the first to be prospectively developed and validated for AKI admitted in a conventional medical care unit. Based on current parameters, easily collected at time of admission, this score could be a useful tool for physicians and nephrologists to determine the in-hospital death prognosis of this AKI population.

Keywords: Cute kidney injury, In-hospital death, Prognosis score, latrogenesis, Score validation

\section{Background}

Acute kidney injury (AKI) is defined as deterioration of renal function over a short period [1]. This definition has been formalized for optimal data comparison between clinical studies thanks to the 2004 RIFLE [2], 2007 AKIN [3] and 2012 KDIGO [4] classifications. These classifications determine several AKI stages based on either an increase in creatinine or decrease in

\footnotetext{
* Correspondence: jbamoulid@chu-besancon.fr; helene.philippot@orange.fr † Jamal Bamoulid and Hélène Philippot contributed equally to this work. ${ }^{1} \mathrm{CHU}$ Besançon, Department of Nephrology, Dialysis, and Renal Transplantation, F-25030 Besançon, France

Full list of author information is available at the end of the article
}

glomerular filtration rate (GFR) and a decrease in urine output. Moreover, these stages help to stratify the severity of AKI and the risk of in-hospital death [5].

Based on these definitions, epidemiological studies reported incidences of 24.4 and 384.1 per 100,000 inhabitants per year, respectively in dialysis and non-dialysis requiring AKI [6]. A recent meta-analysis including 154 studies based on AKI KDIGO definition reported that $20 \%$ of hospitalized adult patients experience AKI whatever the initial cause of hospitalization [7]. Additionally, the incidence of AKI continuously increases from about $11 \%$ per year, particularly in male and elderly populations [8].

(C) The Author(s). 2019 Open Access This article is distributed under the terms of the Creative Commons Attribution 4.0 International License (http://creativecommons.org/licenses/by/4.0/), which permits unrestricted use, distribution, and 
Despite several advances in therapeutics and substantial progress in the understanding of AKI pathogenesis, the related mortality remains high [9]. Overall in-hospital mortality is about 23\% in adults [7]. In the setting of intensive care units (ICU), AKI-associated mortality ranges from 45 to $73.5 \%$ [10-12]. Interestingly, the etiology of AKI can influence mortality rate; epidemiological studies have shown that AKI secondary to nephrotoxic agents and drugs contributes to death in up to $30 \%$ of cases, which remains high but significantly lower than in other potential etiologies [13-15]. Moreover, AKI is a risk factor contributing to chronic kidney disease (CKD): the annual incidence of chronic dialysis is about 8.6\% after one episode of AKI [16].

Most studies about AKI have been conducted in ICU. These studies have reported sepsis, as well as pulmonary, cardiac, and hepatic failure as independent risk factors for AKI-associated mortality [17-24]. Yet, few epidemiological data are currently available on patients admitted to conventional medical units for AKI. Indeed, among the 154 studies included in the recent meta-analysis of Susantitaphong et al, only 7 included patients from conventional hospitalization units of nephrology [7]. Many aspects of AKI, including etiologies and prognosis, might be different in this group of patients compared to that developing AKI in the ICU setting. Moreover, RIFLE, AKIN or KDIGO classifications are particularly difficult to use in everyday practice among conventional units, particularly the close surveillance of urine output.

In this study, we explored epidemiological and biological characteristics of patients admitted to a conventional medical service for AKI and assessed predictive factors for in-hospital death. Our study aimed to elaborate and validate an in-hospital death prognosis score for AKI admitted in conventional medical care units.

\section{Methods}

\section{Patients}

All patients admitted for AKI to the nephrology unit of the University Hospital of Besançon between January 2001 and December 2004 (score elaboration cohort (EC)) and then between January 2010 and December 2013 (score validation cohort (VC)) were prospectively considered for inclusion.

This study was conducted according to the code of public health and the code of medical ethics (6th January 1978 amended in 2004) concerning research that does not involve the human person (study based on health data); the General Data Protection Regulation 2016-679 on the protection of personal data (GDPR) (27th April 2016) and in particular Article 6.1.a highlighting the principle of consent to the processing of personal data; the law 78-17 (6th January 1978) relating to computer, files and freedoms, modified the so-called IT Law and Freedoms (LIL) and the Reference Methodology MR-004 of the French National Agency regulating Data Protection (CNIL). The number of the declaration of conformity to the reference methodology MR-004, concerning research not involving the human person, studies and evaluations in the field of health, is 2,214,506 v0 of July 24th, 2019. All patients participating in this study received written informed information and the opportunity to oppose the use of their data.

All patients were $\geq 18$ years old at the admission date. AKI was defined either by an increase of $50 \%$ or more in serum creatinine $(\mathrm{SCr})$ in patients with previous normal renal function, or a rapid increase $\geq 100 \mu \mathrm{mol} / \mathrm{l}$ in $\mathrm{SCr}$ for patients with previous chronic kidney disease (CKD) (i.e estimated GFR $<60 \mathrm{~mL} / \mathrm{min} / 1.73 \mathrm{~m} 2$ according to MDRD (Modification of the Diet in Renal Disease) over a period of 12 weeks. If no information was available on previous renal function before admission, clinical circumstances as well as reversibility of renal dysfunction and kidney size (evaluated by ultrasound) were considered to determine the acute nature of renal failure. Patients first admitted to ICU and then transferred to our unit and renal transplant recipients admitted for AKI were excluded.

\section{Methods}

Relevant data were collected at the admission. These included demographic characteristics (gender, age, weight, height), provenance (home, rehabilitation center, nursing home, emergency, other hospital services), clinical setting (history of diabetes, hypertension, congestive heart failure, cirrhosis, cancer), systolic and diastolic blood pressure, fluid overload, oxygen therapy requirement, Glasgow coma scale, urine output (normal, marginal, oligo-anuria), and laboratory data (serum urea, Creatinine, Sodium, Potassium, Bicarbonate, Calcium, Phosphorus, Albumin, C-reactive protein [CRP], Hemoglobin, white blood cell count, coagulation parameters, and urinary protein excretion). Normal urine output was defined as a daily urinary volume equal or above $1000 \mathrm{ml}$; marginal urine output was defined as a daily urinary volume of $400-1000 \mathrm{ml}$ and oligoanuria was defined as a urinary volume below $400 \mathrm{ml}$ per day. Chronic kidney disease was defined as a GFR constantly below 60 $\mathrm{ml} / \mathrm{min} / 1.73 \mathrm{~m}^{2}$ (estimated by MDRD) in the 6 months' period preceding the admission. Etiology (when known), secondary diagnosis, dialysis requirement, renal biopsy, hospitalization duration, and outcomes (secondary transfer, death) were also recorded.

\section{Statistical analysis}

The results were expressed as mean $+/-$ standard deviation. The median and range were given for variables which distribution was not normal. We used a logistic regression model. First, univariate analyses were carried out to examine the relationship between death and 
several potential independent variables. Among the latter, covariates to enter multivariate analyses were selected as follows:

- Continuous variables were tested using Student's t test or Mann-Whitney's non-parametric test.

- Categorical variables were tested using Pearson's chisquare, or Fisher's exact test.

The alpha threshold for covariate selection was 0.20 . These death-related variables with $p$-values $<0.20$ were entered in the multivariate analysis model, medical knowledge of the variables guiding the final choice. Selected covariates were entered the stepwise multipleregression analysis. Starting with many covariates as were chosen (either statistically or otherwise), the software performed backwards stepwise selection, the limit to remove a covariate being ( $\mathrm{p}$-value) 0.10 .

An individual prognosis score was then built from the parameters independently associated with intra-hospital death in the EC cohort. The score discrimination was tested twice using ROC curve and Hosmer \& Lemeshow test (a $p$ value $>0.05$ was considered statistically significant and associated with a good predictability of the score). In a second step, the score was validated in the VC cohort using ROC curve and Hosmer \& Lemeshow test.

\section{Results}

\section{Population characteristics}

The cohorts' characteristics are summarized in Table 1. Twenty-six patients out of 349 without complete data collection at the end of the study were excluded from the EC cohort, and only 323 patients were retained for analysis. There were no missing variables in the VC. Hence 323 and 534 patients were included in the EC and VC cohorts, respectively. The cohorts were comparable for age and about one-half patients were above 75 y-o. Two-third patients were male with about one-half CKD patients. The provenance was majoritarian from emergency room (48\% (EC) vs. 57\% (VC); $p=0.16)$, followed by other hospital units (31\% vs. $34 \%$; $p=0.71$ ). Direct admissions (home) represented 16\% (EC) and 7\% (VC) of all admissions $(p=0.05)$.

\section{AKI etiologies}

The etiologies are detailed in Table 1. Functional AKI was the main cause (46\% (EC) vs. $39 \%(\mathrm{VC}) ; p=0.3)$ : dehydration associated to drugs-induced renal hypoperfusion (i.e. renin-angiotensin-aldosterone blockers. Diuretics or non-steroidal anti-inflammatory drugs) accounted for $21 \%(\mathrm{EC})$ and $17 \%(\mathrm{VC})(p=0.41)$. Acute tubular necrosis (ATN) represented 16\% (EC) and 22\% (VC) $(p=0.28)$ and glomerular disease $7 \%(\mathrm{EC})$ and $14 \%$ (VC) of etiologies $(p=0.09)$.
Table 1 Elaboration (EC) and Validation (VC) cohorts' characteristics

\begin{tabular}{|c|c|c|c|}
\hline & \multicolumn{3}{|c|}{$\mathrm{EC}(n=323) \mathrm{VC}(n=534)$} \\
\hline & $\mathrm{n}(\%)$ & $\mathrm{n}(\%)$ & $p^{a}$ \\
\hline Male gender n. (\%) & $203(63)$ & $342(64)$ & 0.86 \\
\hline Mean age [min - max] & 71.9 [19-99] & 71.3 [18-99] & 0.92 \\
\hline$<50$ & $27(8)$ & $53(10)$ & 0.69 \\
\hline $50-75$ & $135(42)$ & $208(38.5)$ & 0.63 \\
\hline$>75$ & $161(50)$ & $273(52)$ & 0.8 \\
\hline$C K D^{b}$ & $144(45)$ & $285(53)$ & 0.21 \\
\hline $\begin{array}{l}\text { Unknown previous } \\
\text { renal status }\end{array}$ & $0(0)$ & $13(2)$ & 0.12 \\
\hline \multicolumn{4}{|l|}{ Provenance } \\
\hline Home & $53(16)$ & $39(7)$ & 0.05 \\
\hline Emergency & $154(48)$ & $306(57)$ & 0.16 \\
\hline Other hospital unit & $101(31)$ & $181(34)$ & 0.71 \\
\hline Rehabilitation center & $15(5)$ & $8(1)$ & 0.18 \\
\hline \multicolumn{4}{|l|}{ Etiologies } \\
\hline Functional & $149(46)$ & 208 (39) & 0.3 \\
\hline Dehydratation & $46(14)$ & $110(21)$ & 0.23 \\
\hline Drugs & $34(11)$ & $8(2)$ & 0.007 \\
\hline Both & $69(21)$ & $90(17)$ & 0.41 \\
\hline Obstructive & $31(10)$ & $35(7)$ & 0.42 \\
\hline Glomerular disease & $22(7)$ & $74(14)$ & 0.09 \\
\hline Acute tubular necrosis & $51(16)$ & $116(22)$ & 0.28 \\
\hline Post-ischemia & $44(14)$ & $66(12)$ & 0.78 \\
\hline Nephrotoxic agents & $1(0.3)$ & $31(6)$ & 0.02 \\
\hline Rhabdomyolysis & $6(2)$ & $19(4)$ & 0.46 \\
\hline Vascular disease & $5(2)$ & $23(4)$ & 0.25 \\
\hline Multiple myeloma & $21(7)$ & $12(2)$ & 0.13 \\
\hline Cardio-renal syndrome & $24(7)$ & $34(6)$ & 0.78 \\
\hline Hepato-renal syndrome & $2(0.6)$ & $2(0.4)$ & 0.84 \\
\hline Haemorragic fever & $1(0.3)$ & $18(3)$ & 0.1 \\
\hline Unknown & $17(5)$ & $12(2)$ & 0.24 \\
\hline
\end{tabular}

${ }^{\mathrm{a} K h i-s q u a r e ~ t e s t}$

${ }^{\mathrm{b}} \mathrm{GFR}<60 \mathrm{~mL} / \mathrm{min} / 1.73 \mathrm{~m}^{2}$

according to MDRD

\section{Outcomes}

The mean hospitalization durations were $12.6 \pm 14.4$ [ 1 143] (EC) and $12.9 \pm 12.5$ [1-91] (VC) days $(p=0.94)$ (Table 2). Dialysis requirement occurred in $24 \%$ (EC) and $25 \%(\mathrm{VC})$ of patients $(p=0.84)$. Renal recovery during inhospital stay was more often complete in the EC compared to the VC cohort ( 65 vs. $45 \% ; p=0.004$ ).

Sixteen percent (EC) and $9 \%(\mathrm{VC})$ of patients died during their stay $(p=0.15)$. The main causes of inhospital death were sepsis (46\% (EC) vs. $43 \%$ (VC); $p=$ $0.74)$, cardio-pulmonary failure (21\% (EC) vs. $27 \%$ (VC); $p=0.35)$, and multiorgan failure $(14 \%$ (EC) vs. $13 \%(\mathrm{VC})$; 
Table 2 Outcomes of the elaboration (EC) and validation (VC) cohorts

\begin{tabular}{|c|c|c|c|c|c|}
\hline & $E C(n=323)$ & & $V C(n=534)$ & & \\
\hline & $n$ & $\%$ & $\mathrm{n}$ & $\%$ & $p^{a}$ \\
\hline Hospitalization duration ${ }^{\mathrm{b}}$ & $12.6[1-143]$ & & $12.9[1-91]$ & & 0.94 \\
\hline Renal biopsy & 38 & 12 & 76 & 14 & 0.59 \\
\hline Extrarenal depuration requirement & 76 & 24 & 132 & 25 & 0.84 \\
\hline Death & 50 & 16 & 48 & 9 & 0.15 \\
\hline sepsis & 23 & 46 & 21 & 44 & 0.74 \\
\hline cardio-pulmonary failure & 10 & 21 & 13 & 27 & 0.32 \\
\hline haemorrage & 7 & 14 & 3 & 6 & 0.06 \\
\hline multiorgan failure & 7 & 14 & 6 & 13 & 0.75 \\
\hline other causes of death & 3 & 7 & 5 & 11 & 0.36 \\
\hline Complete renal recovery ${ }^{c}$ & 179 & 65 & 219 & 45 & 0.004 \\
\hline Chronic dialysis & 7 & 3 & 48 & 10 & 0.03 \\
\hline Destination & & & & & \\
\hline home & 149 & 46 & 307 & 57 & 0.21 \\
\hline other conventional unit & 77 & 24 & 101 & 19 & 0.21 \\
\hline rehabilitation center & 45 & 14 & 61 & 11 & 0.44 \\
\hline $\mathrm{ICU}$ & 3 & 1 & 17 & 3 & 0.21 \\
\hline
\end{tabular}

a Khi-square test

b days

c death-censored

$p=0.32$ ). After hospitalization, $46.1(\mathrm{EC})$ and $57.4(\mathrm{VC})$ \% patients came back home, 23.8 (EC) and 18.9 (VC) \% were secondarily transferred in another conventional medical unit. Only 0.8 (EC) and 3.3 (VC) \% patients were admitted in an ICU, mainly for septic shock.

The comparison of dead and alive patients' characteristics are summarized in the Additional file 1: Table S1.

\section{Elaboration and validation of the in-hospital death prognosis score}

We analyzed all clinical and biological admission parameters significantly associated with in-hospital death in the EC. In multivariate analysis, multiple myeloma, low diastolic blood pressure, low Glasgow score, oxygen requirement, fluid overload, high phosphate levels, elevated white blood cell count, and low prothrombin time were significantly associated with in-hospital death (Table 3). We developed a score based on the ponderation coefficient of each associated parameters independently associated to in-hospital death from the multivariate logistic regression and obtained an equation named Probability of in-hospital death $(P($ id $)):(P($ id $)=$ 7.75-0.563*Glasgow score $-0.025 *$ diastolic blood pressure $+2.26 *$ oxygen therapy $+0.68 *$ fluid overload + $0.00007 *$ white blood cell count $+1.021 *$ serum phosphate $-0.016 *$ prothrombin time +1.72 (if presence of multiple myeloma)).

The score applied to the $\mathrm{VC}$ resulted in a ROC curve with an AUC of $0.877 \pm 0.0253 \quad(p<0.0001)$. The contingency tables comparing expected to observed death proportions in 10 patient groups randomly extracted from the VC did not show any good predictive power of the $\mathrm{P}$ (id) score and the Hosmer and Lemeshow test was not statistically significant $(p<0.0001)$ (data not shown). This suggested the absence of good calibration of the prognosis score equation derived from the EC applied to the VC.

To improve the calibration of our score we compared admission parameters significantly associated with in-hospital death in both cohorts. The parameters independently associated with in-hospital death were comparable except for white blood cell count and serum phosphate which were not associated with in-hospital death in the VC. We therefore built a new EC-derived in-hospital death prognosis score named $\mathrm{P}_{2}(\mathrm{id})$ after suppression of white blood cell count and serum phosphate $(P 2(i d)=7.75-0.563$ "Glasgow score $-0.025 *$ diastolic blood pressure $+2.26 *$ oxygen therapy +0.68 * fluid overload -0.016 * prothrombin time + 1.72 (if presence of multiple myeloma)). We first applied the $\mathrm{P}_{2}$ (id) score in the EC cohort: the AUC was $0.872+/-$ $0.0275(p<0.0001)$ (Fig. 1). The Hosmer and Lemeshow test was statistically significant with a good adequation between expected and observed deaths $(p=0.94)$ (Additional file 2: Table S2). Thus, we applied the $\mathrm{P}_{2}(\mathrm{id})$ score in the VC: the AUC was $0.845+/-0.0295$ (p<0.0001) (Fig. 2). The Hosmer and Lemeshow test was statistically significant with a good adequation between expected and observed deaths $(p=0.19)$ (Table 4). 
Table 3 In-hospital death associated clinical and biological parameters in univariate and multivariate logistic regression in the elaboration cohort

\begin{tabular}{|c|c|c|}
\hline Parameter & Monovariate analysis & Multivariate analysis \\
\hline Male gender & $p=0.859$ & \\
\hline Age & $p=0.014$ & \\
\hline CKD (GFR < $60 \mathrm{ml} / \mathrm{min} / 1.73 \mathrm{~m} 2)$ & $p=0.328$ & \\
\hline Provenance & $p=0.517$ & \\
\hline Multiple myeloma & $p<0.001$ & $16.9[2.1-140.7] p=0.009$ \\
\hline Systolic blood pressure & $p<0.001$ & \\
\hline Diastolic blood pressure & $p<0.001$ & $0.94[0.88-0.98] p=0.014$ \\
\hline Glasgow score & $p<0.001$ & $0.62[0.40-0.95] p=0.030$ \\
\hline Urine output & $p<0.001$ & \\
\hline Oxygen therapy & $p<0.001$ & $8.6[2.8-26.5] p<0.001$ \\
\hline Fluid overload & $p<0.001$ & $2.87[1.11-7.37] p=0.030$ \\
\hline urea & $p=0.656$ & \\
\hline creatinine & $p=0.199$ & \\
\hline sodium & $p=0.031$ & \\
\hline potassium & $p=0.551$ & \\
\hline bicarbonate & $p=0.729$ & \\
\hline Adjusted calcemia & $p=0.011$ & \\
\hline phosphoremia & $p<0.001$ & $2.34[1.24-4.42] p=0.009$ \\
\hline albuminemia & $p=0.001$ & \\
\hline C-reactive protein & $p=0.113$ & \\
\hline Hemoglobin & $p=0.413$ & \\
\hline White blood cell count $\left(/ \mathrm{mm}^{3}\right)$ & $p=0.010$ & $1.00[1.00-1.00] p=0.018$ \\
\hline Prothrombin time & $p<0.001$ & $0.97[0.94-0.99] p=0.019$ \\
\hline Thromboplastin time & $p=0.029$ & \\
\hline Fibrinogen & $p=0.554$ & \\
\hline
\end{tabular}

\section{Discussion}

Most patients with AKI are admitted to conventional units. However, most studies have so far been conducted in the ICU setting [17-24], and therefore very few data exist on AKI in patients admitted to conventional medical units. Our study provides data on epidemiological aspects as well as etiology and outcome of AKI in a conventional unit of nephrology. Furthermore, our prospective study on AKI in two 4 year-period independent cohorts consisted in the elaboration of a score, based on simple available admission clinical and biological parameters, to stratify individual risk of in-hospital death and thus to evaluate the severity of the AKI episode at patient's admission. Inhospital death was 15.5 and $8.9 \%$, respectively in the EC and VC. Multiple myeloma, diastolic blood pressure, Glasgow score, oxygen therapy, fluid overload and prothrombin time were parameters at admission independently associated with the risk of in-hospital death. The prognosis death score derived from these parameters shows a good AUC in both cohorts. This is to our knowledge the first score established from patients admitted to a conventional nephrology unit for AKI.

Our data confirmed that AKI is a disease of the elderly; nearly half patients were 75 years-old or older. More than half patients were admitted from emergency room with many functional AKI. Consequently, comorbidities including cardiovascular disease, cancer and CKD were highly prevalent in this population, and this might also explain why drug nephrotoxicity was found to be the major cause of AKI. This underscores the need for a careful selection of potentially nephrotoxic medications in the elderly in addition to close monitoring and dose adaptation of drugs if relevant. Despite a median age over 75 years-old, our analysis did not reveal age as an independent risk factor for inhospital death. Recent reports on AKI in conventional medical units also describe comparable proportions of old patients, much more than what is reported in ICU studies [12]. The elderly, so as the presence of cardiovascular or neoplastic comorbidities, could be one of the causes for contraindications of the patients' admission in ICU. This 


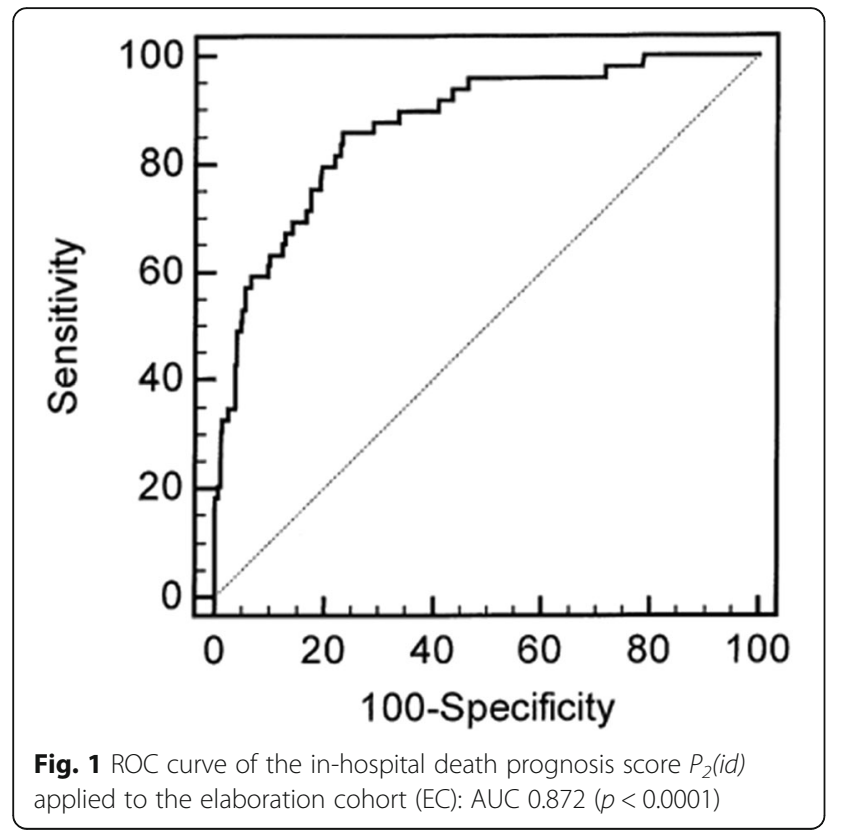

could explain why old patients with AKI are more represented in cases admitted to conventional medical units. About 50\% were CKD patients, highlighting renal diseases as a major risk factor for AKI as reported by others [25]. The secondary transfer from another conventional hospitalization unit in one third cases demonstrates the frequent iatrogenic origin of AKI. However iatrogenic AKI were not associated with poorer survival compared to community-acquired ones as reported by others [26-30].

The analysis of causes also showed high proportion of age-related AKI. Functional AKI remains the main

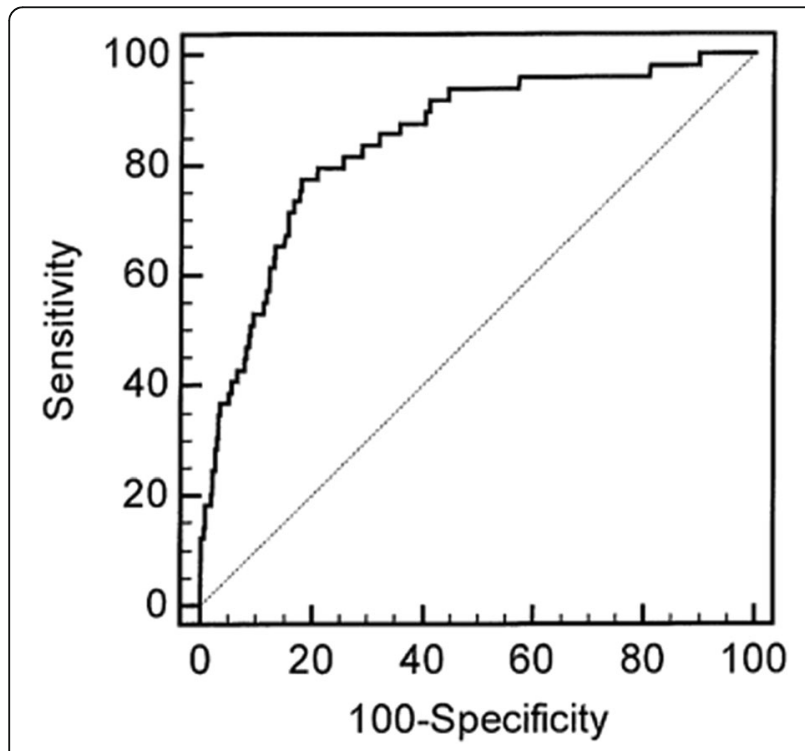

Fig. 2 ROC curve of the in-hospital death prognosis score $P_{2}$ (id) applied to the validation cohort (VC): AUC $0.845(p<0.0001)$
Table 4 Contingency tables after application of the in-hospital death score $\mathrm{P}_{2}(\mathrm{id})$ to the validation cohort using Hosmer and Lemeshow test

\begin{tabular}{lll}
\hline Group & Expected deaths & Observed deaths \\
\hline 1 & 1.694 & 1 \\
2 & 1.745 & 1 \\
3 & 1.737 & 0 \\
4 & 1.779 & 1 \\
5 & 1.838 & 0 \\
6 & 1.955 & 4 \\
7 & 2.393 & 3 \\
8 & 4.067 & 6 \\
9 & 7.883 & 12 \\
10 & 23.908 & 21 \\
\hline Test Hesmer \& Lemeshow $p=0.19$ &
\end{tabular}

cause, related to medicines such as NSAIDs, ACE inhibitors, ARA 2 or diuretics. Older age and polypharmacy are the cornerstone of functional AKI as reported by Anderson et al in a recent meta-analysis [31]. ATN were the second major cause, mainly due to prolonged ischemia or shock. Noteworthy, obstructive etiologies only represented $10 \%$ of cases in an old manly cohort, suggesting local recruitment bias: those patients are often first addressed to the urologist. In other studies, obstructive nephropathy and acute tubular necrosis also greatly contributed to AKI [14]. ATN, hepatorenal and cardiorenal syndromes, multiple myeloma were more observed in deceased compared to surviving patients, yet only multiple myeloma remained independently associated with death. Indeed, whatever the underlying mechanism, renal lesions are of bad prognosis during multiple myeloma. Moreover, those patients are more prone to sepsis because of their immunosuppressive status related to the disease itself or secondary to chemotherapy. Chertow et al showed immunosuppression as a major factor of death in ATN-associated AKI [32]. Selby and colleagues [26] described neoplasia as the third cause of death (after sepsis and cardiovascular events) during an AKI episode.

Renal replacement therapy was performed in $25 \%$ of AKI cases, and dialysis requirement was more frequent in deceased patients. Mesropian et al [33] reported only 3.6 and $5.1 \%$ of dialyzed patients, while Schissler et al [29] described 5.5 and $5.9 \%$, respectively in community- and hospital-acquired AKI. On the contrary, 42 and $47 \%$ of cases were dialyzed in a Chinese report [30], yet including ICU patients. This shed light on the extreme subjective criteria for dialysis initiation, probably depending on the physician and the comorbidities and age of patients. Hsu et al demonstrated that older patients with high number of comorbidities are less prone to benefit from invasive 
procedures accompanying renal replacement therapy [6]. Interestingly, a recent study showed a lower in-hospital mortality when physicians adhere to an algorithm providing recommendations on RRT initiation, yet only for low disease severity cases [34].

Mortality rate for AKI patients in ICU is reported to be as high as $50 \%$ in most studies, likely a reflection of multiple comorbidities [9]. We observed a significantly lower mortality rate in our patients, which was expected. Nevertheless, AKI remains a potentially fatal disease, even in patients not requiring admission to ICU, with an overall mortality rate of about $10 \%$, mainly from sepsis and cardiopulmonary failure when pooling our 2 cohorts. Two recent studies reported 10.8\% [35] and 21.9\% [26] death with comparable proportions of death causes. Our study confirmed that, in addition to certain causes of AKI, coexistence of non-renal organ failure is a powerful predictor of death in patients with AKI: diastolic blood pressure better reflects mean arterial pressure [36] and hypotension (systolic blood pressure) was earlier integrated to SHARF prognosis score for AKI [37], helping physicians to take decision about patient admission in ICU; low Glasgow score is significantly associated with death in our study confirming what was earlier reported by Liano et al [38]; oxygen requirement is often integrated to AKI prognosis scores developed in ICU, where requirement to artificial ventilation is needed in cardiac or pulmonary failures and systematically associated with death $[19,32,37-40]$, yet it could also reflect fluid overload, parameter we also reported as an independent risk factor for death in our study and integrated to our score. Indeed, several reports in ICU demonstrated that a fluid overload defined as a $10 \%$ increase in body weight was associated with death and non-renal recovery after AKI [41, 42]. A recent metaanalysis reported positive fluid balance as a parameter associated with multiorgan failure (i.e. brain, cardiac, pulmonary, hepatic, digestive, renal and skin) and suggested systematic early requirement to renal replacement therapy when diuretics are not efficient to control fluid overload [43].

There are limitations to our study. Firstly, in patients with previous renal impairment, the definition of AKI as an acute increase of $100 \mu \mathrm{mol} / \mathrm{L}$ could seem arbitrary and introduce a selection bias in our study. In fact, the inclusion of patients in the first cohort (EC) started in 2001. There was no clear universal laboratory definition. No real value of acute increase in serum creatinine was available for patients with previous renal impairment. Hence, we chose to arbitrary double the creatinine value increase in patients with previous kidney impairment as compared with what was defined for patients with previous normal renal function in KDIGO. Later, Singri et al. in 2003 [44] and Lameire et al. in 2005 [45] defined acute kidney impairment as an acute and durable increase in serum creatinine of $44.2 \mu \mathrm{mol} / \mathrm{l}$, if basal serum creatinine was below $221 \mu \mathrm{mol} / \mathrm{l}$ or an increase in serum creatinine above $20 \%$ of the basal creatinine, if its value was above $221 \mu \mathrm{mol} / \mathrm{l}$. To keep the prospective design of our study and to respect the same design for the $\mathrm{VC}$, we did not change the initial definition for patients with previous renal impairment. Nevertheless patients who were admitted to our ward for AKI had rarely an increase in serum creatinine below $100 \mu \mathrm{mol} / \mathrm{L}$. Thus, we should have missed little number of AKI cases, as the other cases were often managed as ambulatory patients. Secondly, this is a single center epidemiological study and it is then possible that local circumstances have affected the spectrum of etiologies of AKI found in this population. In fact, our university hospital is considered a tertiary center, and some of the patients included in this study have been transferred from smaller regional medical centers for different reasons (e.g. failure of preliminary treatment or need for plasma exchange). Therefore, severity of AKI as well as outcome and mortality might have been affected. Thirdly, in most cases, the etiology of AKI has been determined based on clinical picture and laboratory data without histologic confirmation. However, it can be considered the routine practice and standard of care in a conventional unit where all patients do not undergo a kidney biopsy.

Our prognosis score was built after completion of all inclusions on two prospective and time-independent cohorts with few missing data and thus was free from recruitment or intervention biases. Our primary outcome was death and could not suffer from judgment bias. We strictly respected the policy for the elaboration and validation steps to build our score. Nevertheless, we had to adjust the equation of our score derived from the elaboration cohort because of an imperfect match between expected (calculated by the score) and observed events after application of the equation in the validation cohort. Both cohorts were not strictly comparable as recruitment has changed between the 2 periods. Etiologies of AKI were differently represented for functional AKI related to medications ( 1.5 vs $10.5 \% ; p=0.007$, respectively in the $\mathrm{VC}$ and the EC) and ATN related to medications toxicity ( 5.8 vs $0.3 \% ; p=0.03$, respectively in the $\mathrm{VC}$ and the EC). These differences probably explain why total renal recovery was significantly lower and permanent renal death significantly higher in the VC. Moreover serum phosphate and white blood cell count were different between both cohorts. Serum phosphate ranges from 0.68 to 5.35 (mean value: $1.79 \pm 0.66 \mathrm{mmol} / \mathrm{L}$, median $1.65 \mathrm{mmol} / \mathrm{L}$ ) in the EC and from 0.35 to $2.74 \mathrm{mmol} / \mathrm{L}$ (mean value $1.76 \pm 0.59 \mathrm{mmol} / \mathrm{L}$, median 1.74 ) in the VC. WBC count ranges from 2000 to $34,400 / \mathrm{mm}^{3}$ (mean value: $10,175 \pm 5145 / \mathrm{mm}^{3}$, median $8800 / \mathrm{mm}^{3}$ ) in 
the EC and from 600 to $79,000 / \mathrm{mm}^{3}$ (mean value 10, $401 \pm 9000 / \mathrm{mm}^{3}$, median $6352 / \mathrm{mm}^{3}$ ) in the VC. Thus these two variables had to be removed in order to agree in both populations.

Although, the first score built in the elaboration cohort was predictive of death in both cohorts, its discriminative power was low. Suppression of two variables improved discrimination ability. This pragmatic approach is based on feedback from observation to improve the model. We finally compared independent death-associated factors of each cohort to only retain 7/ 9 common factors to both cohorts. Thus, the second equation was built from the elaboration cohort and validated in both cohorts with a good prediction of events in the validation cohort. Our score is highly specific but weakly sensitive, with decreased proportion of false positive cases. This could potentially help clinicians to better discriminate between high and low risk patients of inhospital death.

Yet, if we here demonstrated the time validation of our score, we could not affirm its complete validation, due to the monocentric design of our study. A further validation in an independent conventional nephrology unit is needed now before its use in clinical practice. Furthermore, the capability of our score to discriminate between patients, either as a clinical decision tool for ICU admission, or for renal replacement therapy initiation is not demonstrated and should be used in future studies to demonstrate its clinical relevance.

\section{Conclusion}

Our in-hospital death prognosis score is the first to be prospectively developed and validated for AKI admitted in conventional care units. Based on current parameters, easily collected at time of admission, this score could be a useful tool for physicians and nephrologists to determine the in-hospital death prognosis of this AKI population.

\section{Supplementary information}

Supplementary information accompanies this paper at https://doi.org/10. 1186/s12882-019-1610-9.

Additional file 1: Table S1. Comparison between dead and alive patients pooling patients from elaboration and validation cohorts. (DOCX $15 \mathrm{~kb})$

Additional file 2: Table S2. Contingency tables after application of the in-hospital death score $\mathrm{P}_{2}$ (id) to the elaboration cohort using Hosmer and Lemeshow test. (DOCX $12 \mathrm{~kb}$ )

\section{Abbreviations}

AKI: Acute kidney injury; ATN: Acute tubular necrosis; CKD: chronic kidney disease; CRP: C-reactive protein; EC: elaboration cohort; GFR: glomerular filtration rate; ICU: intensive care units; MDRD: Modification of the Diet in Renal Disease; P (id): Probability of in-hospital death; SCr: serum creatinine; VC: validation cohort

\section{Acknowledgements}

Not applicable.

\section{Authors' contributions}

$J B$ and $D D$ participated in research design. JB, HP, AK, BV, TC, CC, ND, MY, CR, CBV, JMC, and DD participated in patients' recruitment and data acquisition. $\mathrm{DD}, \mathrm{JB}$ and HP participated in data analysis. JB, HP, DD and AK participated in writing the article. All authors have read and approved the manuscript.

\section{Funding}

None.

\section{Availability of data and materials}

The datasets used and/or analysed during the current study are available from the corresponding author on reasonable request.

\section{Ethics approval and consent to participate}

A formal ethics approval is not necessary because this study does not involve the human person but uses only health data. In accordance with European and French legislation, "(French translation) reference methodology MR-004 of the French National Agency regulating Data Protection (CNIL) covers the processing of personal data for purposes of study, evaluation or research that does not involve the individual. Specifically, these are studies that do not meet the definition of research involving the human person, particularly studies on the use of data" (Deliberation $n^{\circ} 2018-155$ of May 3, 2018 published in the Official Journal of the French Republic n0160 of July 13, 2018, text $\left.n^{\circ} 110\right) . "$ In accordance with the MR-004 of the French National Agency regulating Data Protection (CNIL), an administrative permission was required to access the raw data. Hence, there was no implication of any ethic comity to get permission to access the raw data. All patients participating in this study received written informed information and the opportunity to oppose the use of their data.

Consent for publication

Not applicable.

Competing interests

The authors declare that they have no competing interests.

\section{Author details}

${ }^{1} \mathrm{CHU}$ Besançon, Department of Nephrology, Dialysis, and Renal Transplantation, F-25030 Besançon, France. ' UMR1098, Federation hospitalo-universitaire INCREASE, F-25020 Besançon, France. ${ }^{3}$ Faculté de Médecine et de Pharmacie, Université de Franche-Comté, F-25020 Besançon, France. ${ }^{4}$ Structure Fédérative de Recherche, SFR FED4234, F-25000 Besançon, France. ${ }^{5}$ Department of Medicine, University of Florida, Gainesville, Florida, USA.

Received: 8 March 2019 Accepted: 29 October 2019

Published online: 21 November 2019

\section{References}

1. Payen D, Berton C. Acute renal failure: epidemiology. incidence and prognostic criteria. Ann Fr Anesth Reanim. 2005;24(2):134-9.

2. Bellomo R, Ronco C, Kellum JA, Mehta RL, Palevsky P. Acute Dialysis Quality Initiative workgroup. Acute renal failure definition. Outcomes measures. Animal models. Fluid therapy and information technology needs: the second international consensus conference of the acute Dialysis quality initiative (ADQI) group. Crit Care. 2004;8(4):R204-12.

3. Mehta RL, Kellum JA, Shah SV, et al. Acute kidney injury network : report of an initiative to improve outcomes in acute kidney injury. Crit Care. 2007; 11(2):R31.

4. Kidney Disease. Improving Global Outcomes (KDIGO) Acute Kidney Injury Work Group. KDIGO Clinical Practice Guideline for Acute Kidney Injury. Kidney Int Suppl. 2012;2:S1-S138.

5. Wang HE, Jain G, Glassock RJ, Warnock DG. Comparison of absolute serum creatinine changes versus kidney Disease : improving global outcomes consensus definitions for characterizing stages of acute kidney injury. Nephrol Dial Transplant. 2013;28(6):1447-54. 
6. Hsu CY, McCulloch CE, Fan D, Ordoñez JD, Chertow GM, Go AS. Community-based incidence of acute renal failure. Kidney Int. 2007;72(2): 208-12.

7. Susantitaphong P, Cruz DN, Cerda J, Abulfaraj M, Alqahtani F, Koulouridis I, et al. World incidence of AKl: a meta-analysis. CJASN. 2013;8(9):1482-93.

8. Xue JL, Daniels F, Star RA, et al. Incidence and mortality of acute renal failure in Medicare beneficiaries, 1992 to 2001. JASN. 2006;17(4):1135-42.

9. Schrier RW, Wang W, Poole B, Mitra A. Acute renal failure: definitions, diagnosis, pathogenesis, and therapy. J Clin Invest. 2004;1 14(1):5-14.

10. Mehta RL, Pascual MT, Soroko S, Savage BR, Himmelfarb J, Ikizler TA, et al. Spectrum of acute renal failure in the intensive care unit: the PICARD experience. Kidney Int. 2004;66(4):1613-21.

11. Mehta RL, McDonald B, Gabbai F, et al. Nephrology consultation in acute renal failure: does timing matter? Am J Med. 2002;113(6):456-61.

12. Singh TB, Rathore SS, Choudhury TA, Shukla VK, Singh DK, Prakash J. Hospital-acquired acute kidney injury in medical. Surgical. And intensive care unit: a comparative study. Indian J Nephrol. 2013;23(1):24-9.

13. Rihal CS, Textor SC, Grill DE, et al. Incidence and prognostic importance of acute renal failure after percutaneous coronary intervention. Circulation. 2002;105(19):2259-64.

14. Levy EM, Viscoli CM, Horwitz RI. The effect of acute renal failure on mortality. A cohort analysis. JAMA. 1996;275(19):1489-94.

15. Behrend T, Miller SB. Acute renal failure in the cardiac care unit: etiologies, outcomes, and prognostic factors. Kidney Int. 1999;56(1):238-43.

16. Coca SG, Singanamala S, Parikh CR. Chronic kidney disease after acute kidney injury: a systematic review and meta-analysis. Kidney Int. 2012;81(5): 442-8.

17. Dharan KS, John GT, Antonisamy B, Kirubakaran MG, Jacob CK. Prediction of mortality in acute renal failure in the tropics. Ren Fail. 2005;27(3):289-96.

18. Carbonell N, Blasco M, Sanjuan R, Garcia-Ramon R, Blanquer J, Carrasco AM. Acute renal failure in critically ill patients. A prospective epidemiological study. Nefrologia. 2004;24(1):47-53.

19. Lins RL, Elseviers M, Daelemans R, et al. Prognostic value of a new scoring system for hospital mortality in acute renal failure. Clin Nephrol. 2000;53(1):10-7.

20. Yuasa S, Takahashi N, Shoji T, et al. A simple and early prognostic index for acute renal failure patients requiring renal replacement therapy. Artif Organs. 1998;22(4):273-8.

21. Neveu $H$, Kleinknecht $D$, Brivet $F$, Loirat $P$, Landais $P$. Prognostic factors in acute renal failure due to sepsis. Results of a prospective multicentre study. Nephrol Dial Transplant. 1996;11(2):293-9.

22. Chertow GM, Christiansen CL, Cleary PD, Munro C, Lazarus JM. Prognostic stratification in critically ill patients with acute renal failure requiring dialysis. Arch Intern Med. 1995;55(14):1505-11.

23. Lohr JW, McFarlane MJ, Grantham JJ. A clinical index to predict survival in acute renal failure patients requiring dialysis. Am J Kidney Dis. 1988;11(3): 254-9.

24. Rasmussen HH, Pitt EA, Ibels LS, McNeil DR. Prediction of outcome in acute renal failure by discriminant analysis of clinical variables. Arch Intern Med. 1985;145(11):2015-8

25. Hsu CY, Ordoñez JD, Chertow GM, Fan D, McCulloch CE, Go AS. The risk of acute renal failure in patients with chronic kidney disease. Kidney Int. 2008; 74(1):101-7.

26. Selby NM, Kolhe NV, Mclntyre CW, et al. Defining the cause of death in hospitalised patients with acute kidney injury. PLoS One. 2012;7(11):e48580.

27. Wonnacott A, Meran S, Amphlett B, Talabani B, Phillips A. Epidemiology and outcomes in community-acquired versus hospital-acquired AKI. Clin J Am Soc Nephrol. 2014;9(6):1007-14

28. Sesso R, Roque A, Vicioso B, Stella S. Prognosis of ARF in hospitalized elderly patients. Am J Kidney Dis. 2004;44(3):410-9.

29. Schissler MM, Zaidi S, Kumar H, Deo D, Brier ME, McLeish KR. Characteristics and outcomes in community-acquired versus hospital-acquired acute kidney injury: community-acquired acute kidney injury. Nephrology. 2013; 18(3):183-7.

30. Wang Y, Cui Z, Fan M. Hospital-acquired and community-acquired acute renal failure in hospitalized Chinese: a ten-year review. Ren Fail. 2007;29(2):163-8.

31. Anderson S, Eldadah $B$, Halter JB, et al. Acute kidney injury in older adults. J Am Soc Nephrol. 2011;22(1):28-38.

32. Chertow GM, Lazarus JM, Paganini EP, Allgren RL, Lafayette RA, Sayegh MH. Predictors of mortality and the provision of dialysis in patients with acute tubular necrosis. The Auriculin Anaritide acute renal failure study group. J Am Soc Nephrol. 1998;9(4):692-8.
33. Mesropian PJD, Kalamaras JS, Eisele G, Phelps KR, Asif A, Mathew RO. Longterm outcomes of community-acquired versus hospital-acquired acute kidney injury: a retrospective analysis. Clin Nephrol. 2014;81(03):174-84.

34. Mendu ML, Ciociolo GR Jr, McLaughlin SR, et al. A decision-making algorithm for initiation and discontinuation of RRT in severe AKI. Clin J Am Soc Nephrol. 2017;12(2):228-36.

35. Wang HE, Muntner P, Chertow GM, Warnock DG. Acute kidney injury and mortality in hospitalized patients. Am J Nephrol. 2012;35(4):349-55.

36. Guide des chiffres et formules utiles en pratique médicale. Messaï E.Paris: Arnette Blackwell; 1995.

37. Lins RL, Elseviers MM, Daelemans $\mathrm{R}$, et al. Re-evaluation and modification of the Stuivenberg hospital acute renal failure (SHARF) scoring system for the prognosis of acute renal failure: an independent multicentre, prospective study. Nephrol Dial Transplant. 2004;19(9):2282-8.

38. Liaño F, Gallego A, Pascual J, et al. Prognosis of acute tubular necrosis: an extended prospectively contrasted study. Nephron. 1993;63(1):21-31.

39. Paganini EP, Halstenberg WK, Goormastic M. Risk modeling in acute renal failure requiring dialysis: the introduction of a new model. Clin Nephrol. 1996;46(3):206-11.

40. Mehta RL, Pascual MT, Gruta CG, Zhuang S, Chertow GM. Refining predictive models in critically ill patients with acute renal failure. J Am Soc Nephrol. 2002:13(5):1350-7.

41. Bouchard J, Soroko SB, Chertow GM, et al. Fluid accumulation, survival and recovery of kidney function in critically ill patients with acute kidney injury. Kidney Int. 2009;76(4):422-7.

42. Teixeira C, Garzotto F, Piccinni P, et al. Fluid balance and urine volume are independent predictors of mortality in acute kidney injury. Crit Care. 2013; 17(1):R14.

43. Prowle JR, Echeverri JE, Ligabo EV, Ronco C, Bellomo R. Fluid balance and acute kidney injury. Nat Rev Nephrol. 2010;6(2):107-15.

44. Singri N, Ahya SN, Levin ML. Acute Renal Failure. JAMA. 2003;289(6):747-51.

45. Lameire N, Van Biesen W, Vanholder R. Acute renal failure. Lancet. 2005; 365(9457):417-30

\section{Publisher's Note}

Springer Nature remains neutral with regard to jurisdictional claims in published maps and institutional affiliations.

Ready to submit your research? Choose BMC and benefit from:

- fast, convenient online submission

- thorough peer review by experienced researchers in your field

- rapid publication on acceptance

- support for research data, including large and complex data types

- gold Open Access which fosters wider collaboration and increased citations

- maximum visibility for your research: over $100 \mathrm{M}$ website views per year

At $\mathrm{BMC}$, research is always in progress.

Learn more biomedcentral.com/submissions 